\title{
Geometrias humanas Os figurinos de Bernardo Monteiro
}

\section{Alexandra Moreira da Silva}

de William Shakespeare,

enc. Ricardo Pais,

TNSJ, 2008

(Sara Carinhas), fot. João Tuna.

Alexandra Moreira

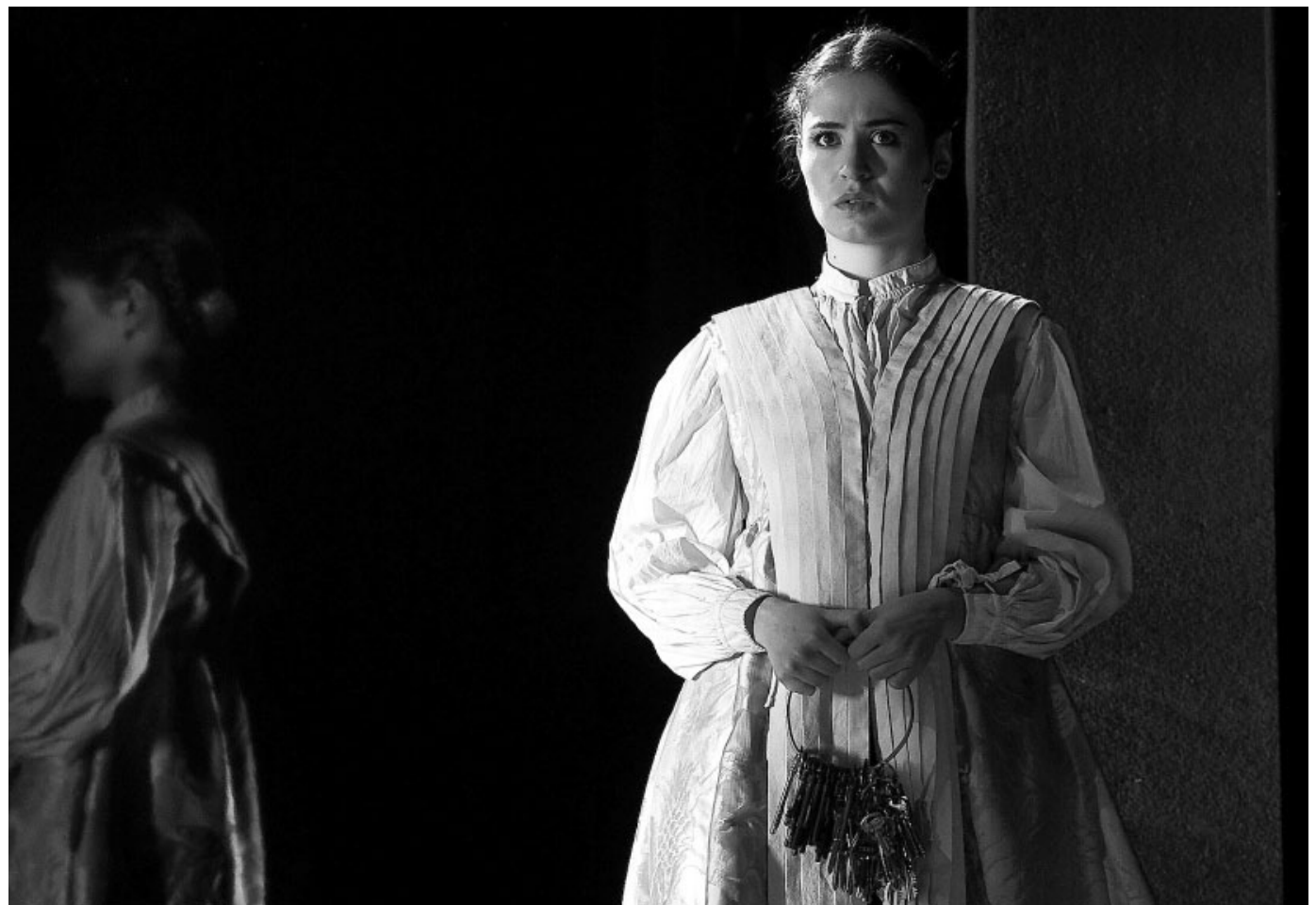

Bernardo Monteiro, cujo percurso discreto se tem vindo a afirmar de forma segura no panorama do teatro português, muito particularmente desde a criação dos figurinos de UBUS, na encenação de Ricardo Pais (2005) e onde facilmente se reconhece uma verdadeira "cenografia à escala humana" (Pavis 1996:163), assina, em 2009, dois trabalhos bastante distintos no Teatro Nacional São João: Tambores na noite, de Bertolt Brecht, e Breve sumário da história de Deus, de Gil Vicente, ambos encenados por Nuno Carinhas, que constituem um excelente exemplo de rigor dramatúrgico e de criatividade na escolha e na conjugação de formas, de cores e de materiais, tornando a valência de figurinos indispensável para a leitura do gestusglobal do espectáculo.

Na nota enviada para a imprensa são evocadas, de forma muitíssimo sintética, algumas das razões que levaram, este ano, o júri da Associação Portuguesa de Críticos de Teatro a atribuir, por unanimidade, uma das Menções Especiais ao figurinista Bernardo Monteiro. Mas há outras talvez menos evidentes - ou menos sintetizáveis - que me permito agora convocar e que organizei em três pontos diferentes, a partir de três citações que, de alguma forma inspiraram esta reflexão.

1. Afinal, o figurino não é o envelope...

"O corpo, afirma Jean-Luc Nancy, é um envelope: ele serve para conter aquilo que depois será necessário desenvolver. 0 desenvolvimento é interminável. 0 corpo finito contém o infinito, que não é nem alma, nem espirito, mas sim o desenvolvimento do corpo" (Nancy 2006:147). 0 trabalho de Bernardo Monteiro mostra-nos precisamente isto: que o figurino é - ou deve ser - o primeiro espaço desse desenvolvimento, da expansão do corpo do actor, do seu movimento, do seu ritmo, da sua respiração. É esta consciência que nos permite reconhecer nos seus trabalhos uma visão plástica sempre à escala humana, que nunca se sobrepõe ao corpo do actor, mas que procura sublinhar o que nele existe de mais evidentemente necessário no contexto do espectáculo - a sua teatralidade.

De facto, Bernardo Monteiro - que entre 2000, altura em que realiza o seu primeiro trabalho como figurinista 

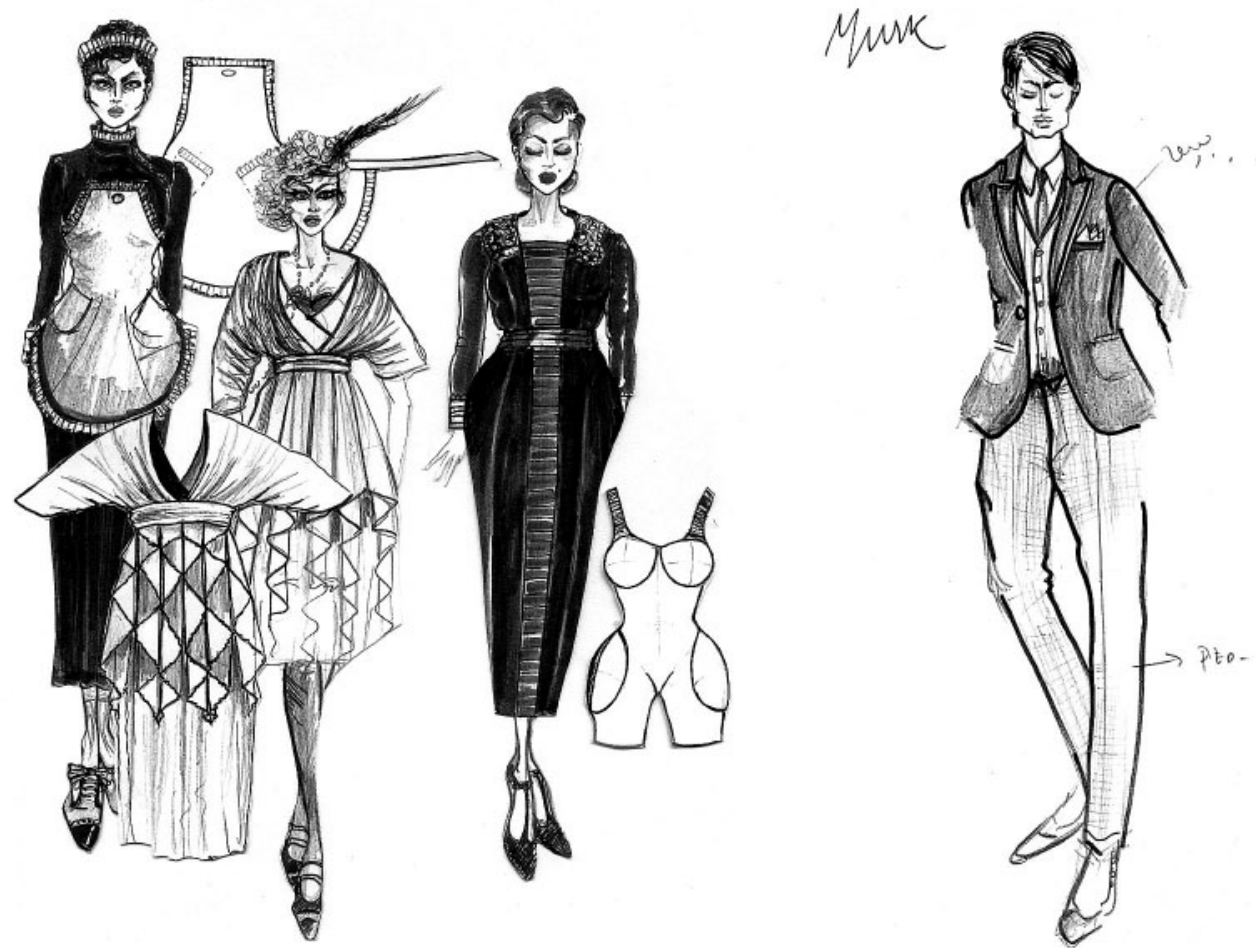

Esboços de Bernardo

Monteiro para figurinos

de Tambores na noite

de Bertolt Brecht,

enc. Nuno Carinhas,

TNSJ, 2009.

((A)tentados, de Martin Crimp, encenação de João Pedro Vaz, numa produção da ASSéDIO) e 2009, realizou 42 criações de figurinos em espectáculos de companhias e/ou estruturas tão diversas quanto As Boas Raparigas..., ASSéDIO, Ensemble, Teatro Nacional São João ou Novo Grupo/Teatro Aberto - sabe que o "corpo é material. É denso. É impenetrável" (Ibidem:145). Veja-se, a título de exemplo, a dupla Kragler (Paulo Freixinho) / Murk (Pedro Almendra) em Tambores na noite (TNSJ, 2009). 0 figurino do primeiro (do qual destacaria as emblemáticas botas de onde Kragler fará escoar um "deserto" de areia num inusitado gesto de contagem do tempo, e uma capa que se apresenta simultaneamente como espaço amplo moldável e como objecto escultórico) transporta a aridez do deserto africano: as pedras, a lama, a areia. É neste espaço que se movimenta um corpo também ele árido, sequioso, onde não vingarão sequer as ideias revolucionárias. Em contrapartida, Murk veste um figurino clássico (fato escuro, camisa branca) que convoca a ascensão social da personagem. Uma vez mais, as botas - desta vez cardadas - e o casaco protector que simbolicamente Anna (Sara Carinhas) vestirá até ao momento em que volta para Kragler, serão os elementos mais emblemáticos e de imediata leitura dramatúrgica.

De referir, ainda, a escolha minuciosa de cores e de materiais (Anna surge com um surpreendente figurino em tons pastel que realça a sua palidez anémica e a muito maeterlinckiana - fragilidade espectral convocada pela interpretação de Sara Carinhas), o justo equilibrio dos volumes (os corpos ligeiramente dilatados do casal burguês Balicke, os tons escuros, as peles e os chapéus que corroboram o tom farsesco adoptado pelos actores Emília Silvestre e Jorge Mota) e a maleabilidade dos tecidos, que abrem espaço a uma corporalidade mais ampla, permitindo, no entanto, ao actor gerir eficazmente esse "infinito que o corpo finito contém".

2. Porque, ainda que funcionais, os figurinos também podem ser "belos"

"É necessário, também, admitir que há sempre alguma coisa de inquietante no belo. Se é sob a forma do apelo, 


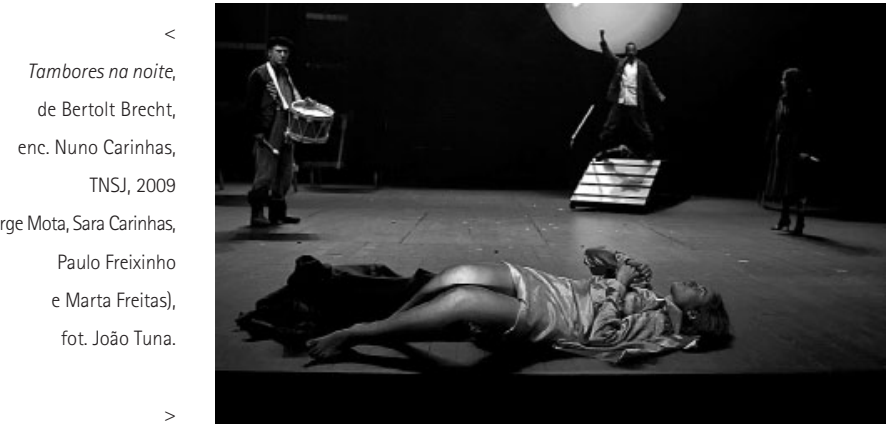

Breve sumário de história

de Deus, de Gil Vicente, enc. Nuno Carinhas,

TNSJ, 2009, fot. João Tuna.

mais do que sob a forma do simples prazer, que a beleza nos agrada, isso é também porque ela nos inquieta" (Nancy 2009a:140). Em Breve sumário da história de Deus (TNSJ 2009), Bernardo Monteiro cria um "figurino-base" em tons pastel, e com formas amplas, praticamente idêntico para todas as personagens que habitam esse Limbo auschwitziano imaginado por Nuno Carinhas (com quem aliás, o figurinista tem colaborado frequentemente; podemos ainda citar as colaborações com encenadores como Ricardo Pais, Rogério de Carvalho, João Lourenço, João Cardoso ou Carlos Pimenta). Mas - e porque Bernardo Monteiro sabe que "[u]m corpo é [também] imaterial. É um desenho, é um contorno, é uma ideia" (Nancy 2006:145) - os figurinos a que vem dando forma são de um pormenor de uma minúcia, francamente inquietantes. Não quero com isto dizer que as suas criações se transformam naquilo a que Roland Barthes chamava "um 'álibi"'. Por outras palavras, que o figurino abandona a sua "função", ou ainda, que se deixa contaminar por essa segunda "doença" apontada pelo crítico francês: "a doença estética, a hipertrofia de uma beleza formal sem relação com a peça" (Barthes 1964:54, 55). Bem pelo contrário, Bernardo Monteiro coloca-se ao serviço do texto e do projecto do encenador; desta cumplicidade inicial, parte para uma ou várias propostas que, de alguma forma, e em determinados momentos, possam, eventualmente, transcender a ideia de partida. Contudo, é nos pormenores que melhor nos apercebemos do seu "perfeccionismo compulsivo": os mantos, as pregas, as nervuras, os plissados, os botões e os botõezinhos, os forros, os bolsos, as tiras dos sapatos, novamente os botões - dos sapatos, as fitas, os laços, as golas, os punhos, as bainhas, a singeleza dos tecidos, ou voltando a Breve sumário da história de Deus, a discretíssima gaze no corpo esbranquiçado da actriz Alexandra Gabriel (A Morte). Enfim, tudo aquilo que "quase" não se vê (vale a pena, ainda assim, assistir ao espectáculo na primeira fila) mas que "se sente", e cujo efeito só é perceptível na sua inquietante globalidade, e na não menos inquietante globalidade do espectáculo. Os pormenores dos figurinos de Bernardo Monteiro contribuem, deste modo, para a coerência das formas, dos tons, para a densidade dos volumes, para o apontamento histórico (veja-se, por exemplo, o figurino do Anjo de Portugal) e/ou dramatúrgico (as asas dos Demónios) ou para a simples abstracção, sublinhando as linhas de força do espectáculo.

Neste ponto, muito teríamos a dizer se recordássemos, entre outros, o já referido UBUs (2005), trabalho em que Bernardo Monteiro recuperava e recriava vários elementos do traje tradicional português, e cujas criações encarnavam o próprio conceito de "Desdramatização da pátria"

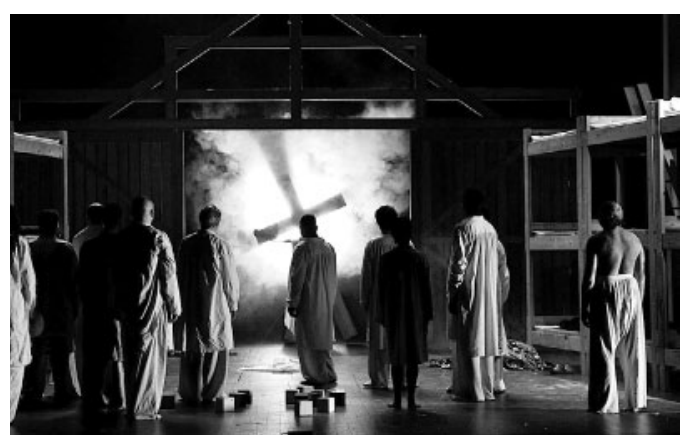

subjacente ao projecto global do espectáculo e à muito singular escrita cénica de Ricardo Pais; ou ainda 0 mercador de Veneza (TNSJ, encenação de Ricardo Pais, 2008) onde os figurinos se destacavam, simultaneamente, pelo contraste, pela coerência dramatúrgica e criativa e - porque não dizê-lo - por uma inquestionável e inquietante "beleza".

\section{Para uma dramaturgia do desenho}

"O desenho não é a forma, é a maneira de ver a forma" (Degas / Nancy 2009b: 22). Antes de desenhar, Bernardo Monteiro lê. Lê o texto. E depois lê, lê, lê. E vê. Muita iconografia e tudo aquilo que possa ter que ver com a época, com o texto, com o contexto. Só depois começa a desenhar. E a conversar (com o encenador). E a modificar (os desenhos). Até ao desenho técnico que leva para o atelier. No atelier, segue todo o processo de criação dos figurinos. Explica a forma - ou melhor, a sua "maneira de ver a forma". Constrói, monta, faz provas. Ao (re)criar, os seus desenhos têm em conta os códigos de representação (por exemplo, de uma época), mas também a liberdade da personagem, a hipótese dramatúrgica convocada pelo encenador e, naturalmente, a sua própria liberdade de criador. Deste modo, afasta-se de todo e qualquer risco de reconstituição arqueológica, garantindo a necessária mas equilibrada ambiguidade criativa, e tendo presente que cada criação deverá ser "suficientemente material para significar e suficientemente transparente para que os seus signos não se tornem parasitas" (Barthes 1964: 61).

0 trabalho, esse, prolonga-se exaustivamente até ao dia da estreia. Por isso, não será estranho vermos Bernardo Monteiro, depois desse primeiro espectáculo - o da "libertação" - (talvez) "em boné, de gola levantada e com as mãos nas algibeiras das calças" - para citar Tambores na noite - (Brecht 2003: 146) sair do teatro (talvez) "a assobiar" e a perguntar descontraidamente: "Que tâmara é aquela tão vermelha?". Ou outra coisa qualquer. Assim. Exactamente como esta. Depois - e só depois - da estreia.

\section{Referências bibliográficas}

BARTHES, Roland (1964), "Les maladies du costume de théâtre", Essais critiques, Paris, Seuil.

BRECHT, Bertolt (2003), Tambores na noite (1922), tradução de Adélia Silva Melo e Jorge Silva Melo, colaboração de José Maria Vieira Mendes e Vera San Payo de Lemos, in Teatro 1, Lisboa, Cotovia.

NANCY, Jean-Luc (2000), Corpus, Paris, Métaillé.

-- (2009a), Dieu, La justice, L'amour, La beauté, Quatre petites conférences, Paris, Bayard.

-- (2009b), Le Plaisir au dessin, Paris, Galilée.

PAVIS, Patrice (1996), L'Analyse des spectacles, Paris, Armand Colin. 